\title{
Avaliação da influência da tempertura na resistência à tração e na resistência ao Impacto Izod em Polimetacrilato de Metila (PMMA)*
}

\author{
Gilmar Cunha da Silva \\ Sérgio Neves Monteiro ${ }^{2}$ \\ Verônica Scarpini Candido ${ }^{3}$ \\ Alisson Clay Rios da Silva ${ }^{4}$
}

\section{Resumo}

O uso cada vez mais frequente do poli metacrilato de metila (PMMA), muitas vezes em substituição ao vidro temperado, se deve a sua alta rigidez, praticidade, leveza e transparência. No entanto, as normas de fabricação atuais na indústria de polímeros recomendam testes específicos nesses materiais. $O$ presente estudo tem o objetivo de testar mecanicamente as propriedades do material Polimetacrilato de Metila (PMMA) em condições que simulem um ambiente muito mais agressivo do que o usual. Para tanto foram realizados testes de espectroscopia na região do infravermelho (FTIR), análise termogravimétrica (TGA), testes de tração e impacto Izod, e análise por Microscopia Eletrônica de Varredura (MEV). Os resultados revelaram que o Polimetacrilato de metila (PMMA) manteve suas propriedades mecânicas em tração até a temperatura de $105^{\circ} \mathrm{C}$. No que se refere à resistência ao impacto, a temperatura influenciou negativamente no desempenho desse polímero.

Palavras-chave: Microscopia Eletrônica de Varredura; Polimetacrilato de Metila; Propriedades Mecânicas.

\section{Evaluation of the influence of temperature on tensile strength and Izod Impact resistance on Poly (Methyl Methacrylate) (PMMA).}

\section{Abstract}

The increasing use of methyl methacrylate (PMMA), often replacing tempered glass, is due to its high rigidity, practicality, lightness and transparency. However, current manufacturing standards in the polymer industry recommend specific tests on these materials. The present study aims to mechanically test the properties of Methyl Polymethacrylate (PMMA) material under conditions that simulate a much more aggressive environment than usual. Infrared spectroscopy (FTIR), thermogravimetric (TGA) tests, Izod traction and impact tests, and Scanning Electron Microscopy (SEM) analysis were performed. The results showed that poly (methyl methacrylate) (PMMA) maintained its tensile mechanical properties up to $105^{\circ} \mathrm{C}$. Regarding the impact strength, the temperature negatively influenced the performance of this polymer.

Keywords: Mechanical Properties; Poly (methyl methacrylate); Scanning Electron Microscopy.

1 Engenheiro de produção, Mestre, Aluno de pós-graduação, Centro Universitário da Zona Oeste (UEZO), Rio de Janeiro - Rio de Janeiro, Brasil.

2 Engenheiro de Materiais, PhD em Engenharia e Ciência dos Materiais, Professor, Programa de Pós-graduação em Engenharia de Materiais/Departamento de Engenharia Mecânica e Materiais, Instituto Militar de Engenharia (IME), Rio de Janeiro, Rio de Janeiro, Brasil.

3 Bióloga, Doutora em Ciência dos Materiais, Professora Adjunta I, Faculdade de Engenharia de Materiais, Universidade Federal do Pará (UFPA), Ananindeua- PA, Brasil.

4 Químico industrial, Doutor em Ciência dos Materiais, Professor Adjunto I, Faculdade de Engenharia de Materiais, Universidade Federal do Pará (UFPA), Ananindeua- PA, Brasil.. 


\section{INTRODUÇÃO}

Polímeros são macromoléculas orgânicas formadas por unidades repetidas chamadas meros e são amplamente empregados em todas as áreas industriais. Essa classe de material pode ter origem natural, como o látex, e artificial como o polipropileno [1-4].

O primeiro polímero 100\% sintético produzido foi a "baquelite" em 1909 e, a partir da sua produção, vários outros polímeros foram sintetizados e, atualmente, a indústria polimérica tem grande expressividade mundial [2].

O polimetacrilato de metila (PMMA), comercialmente conhecido como acrílico, é derivado do ácido acrílico $(\mathrm{CH} 2=\mathrm{CH}-\mathrm{CO}-\mathrm{OH})$ e metacrílico $(\mathrm{CH} 2=\mathrm{C}(\mathrm{CH} 3)-\mathrm{CO}-\mathrm{OH})$ $[2,5]$. É um polímero termoplástico de cadeia linear, amorfa e que pode ser formado por adição e, dependendo da utilização, pode ser produzido por diversos métodos de polimerização como, por exemplo, o de processo em massa ou em suspensão [6].

O PMMA pode ser moldado em forma de objetos plásticos rígidos e, diferentemente da maioria dos termoplásticos, pode ser polimerizado diretamente em um molde sem precisar pela etapa de injeção. Esse polímero apresenta boa claridade ótica, resistência mecânica, boa resistência a agentes atmosféricos e baixa absorção de água [5,7].

O PMMA é sindiotático, cerca de 70 a $75 \%$, e, por ser amorfo, é utilizado como lentes automotivas, dispositivos reflexivos, instrumentos e tampas de eletrodomésticos, material óptico e objetos de decoração [6].

Esse material apresenta resistência à tração apreciável, entretanto, a sua resistência ao impacto não é muito elevada, o que limita sua aplicação. Para melhorar sua resistência ao impacto são empregados artifícios como a copolimerização com polímeros acrílicos de baixo peso molecular [8, 9], todavia, essa técnica resulta na diminuição da claridade ótica. Para atingir boa resistência ao impacto, sem prejudicar a transparência, diversos estudos têm sido realizados na área de nanocompósitos [10-12]. Nos nanocompósitos, as nanopartículas dispersas na matriz polimérica permitem a melhoria do desempenho mecânico e estabilidade térmica sem prejudicar a transparência [5, 13]. Além da técnica de produção de nanocompósitos, outro fator observado é a temperatura de exposição do polímero que pode influenciar nas propriedades mecânicas desse material [5]. Assim, esse estudo tem o objetivo de avaliar o comportamento mecânico do PMMA quando exposto a diferentes temperaturas.

\section{MATERIAIS E MÉTODOS}

O polimetacrilato de metila foi adquirido de uma amostra comercial sob a forma de chapa fundida "cast" em dimensões de 500 × 500 × 6,0mm do fornecedor Isolaplast.

A tabela 1 apresenta as condições de avaliação do Polimetacrilato de metila. As amostras foram separadas em quatro grupos de acordo a temperatura de degradação. 
Tabela 1. Grupos de avaliação

\section{Grupo de avaliação Condições de ensaio}

A Polimetacrilato de metila "como recebido"

B Polimetacrilato de metila após degradação térmica a $85^{\circ} \mathrm{C}$

C Polimetacrilato de metila após degradação térmica a $105^{\circ} \mathrm{C}$

D Polimetacrilato de metila após degradação térmica a $150^{\circ} \mathrm{C}$

Para realizar a degradação térmica, os corpos de prova foram colocados em estufa da DS Diagnóstica durante 4 horas nas temperaturas de 85,105 e 150ㄷ.

Após a etapa de degradação térmica, as mostras foram analisadas por Espectroscopia na região do infravermelho (FTIR) e análise termogravimétrica - TGA (TG/DTG).

A espectroscopia de absorção no infravermelho por transformada de Fourier (FTIR) foi executada pelo Centro Tecnológico de polímeros - CETEPO (Senai-RS), em um espectrômetro da marca Perkin Elmer, Modelo Spectrum One, Faixa Espectral: 4000 a $650 \mathrm{~cm}-1$, Número de Scans: 8, Resolução: $4 \mathrm{~cm}^{-1}$.

A análise termogravimétrica foi realizada em analisador térmico da TA Instrument, modelo 2910 operando a uma taxa de aquecimento de $10^{\circ} \mathrm{C} / \mathrm{min}$ em um intervalo de temperatura de $30-700^{\circ} \mathrm{C}$ e atmosfera de nitrogênio.

Os corpos de prova para os ensaios de tração e impacto Izod foram usinados a partir de chapa fundida de PMMA e solubilizados a uma temperatura de $25^{\circ} \mathrm{C}$ por 16 horas para alivio de tensões residuais causadas pelo processo de usinagem, conforme solicitado pela norma ASTM D788:10 [14].

O ensaio de tração foi realizado em máquina universal de ensaios da marca EMIC, modelo GR 044 seguindo as diretrizes das normas ASTM D638:10 [15]. O ensaio de resitência ao impacto Izod foi executado de acordo com a norma ASTM D256:10 [16] em máquina de ensaio da TINUS OLSEN, modelo Plastic Impact Tester, sendo o entalhe em V de $45^{\circ}$ e $2 \mathrm{~mm}$ de profundidade fabricados por usinagem mecânica com o entalhe produzido em brochadeira.

A análise da região da fratura dos corpos de prova ensaiados por impacto Izod foi realizada em microscópio eletrônico de varredura da marca JEOL, modelo JSM 5800LV.

\section{RESULTADOS E DISCUSSÃO}

A Figura 1 mostra o espectro obtido para a amostra de PMMA como recebido. 


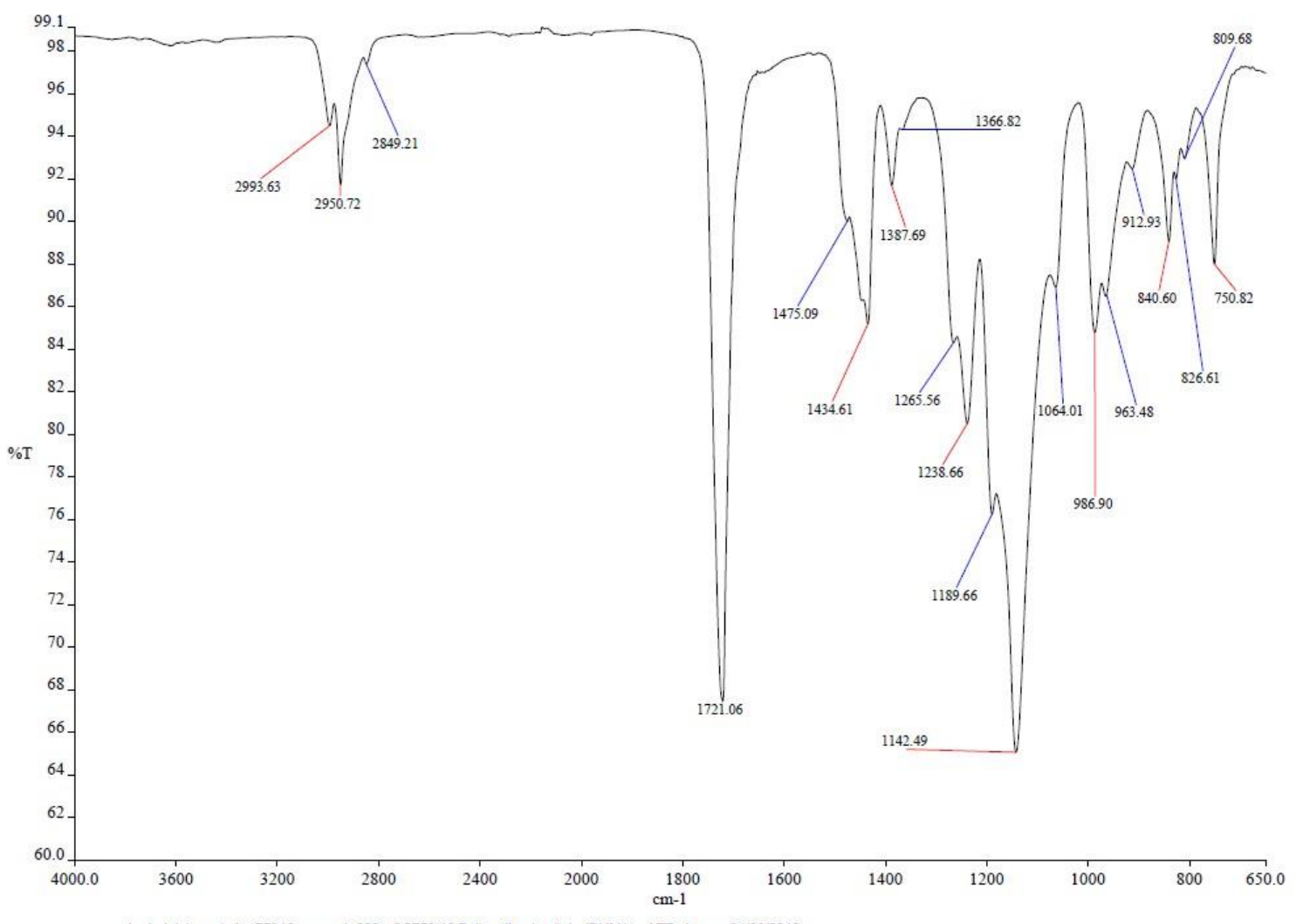

_ c:lpel_datalspectralos75916 pmma_b.002 - OS759/16 Polimetilmetacrilato (PMMA), ATR, Agnes, 01/06/2016

Figura 1. Espectro de infravermelho da amostra PMMA "como recebido".

O PMMA apresenta uma banda intensa em $1726 \mathrm{~cm}-1$ devido ao estiramento simétrico do grupo $\mathrm{C}=\mathrm{O}$. Os picos vibracionais em 1387, 1272 e 987 são atribuídos à deformação O-CH3, e estiramento simétrico C-O e C-O-C do PMMA [17].

A Figura 2 mostra o espectro obtido dos grupos B, C e D tratados termicamente. 


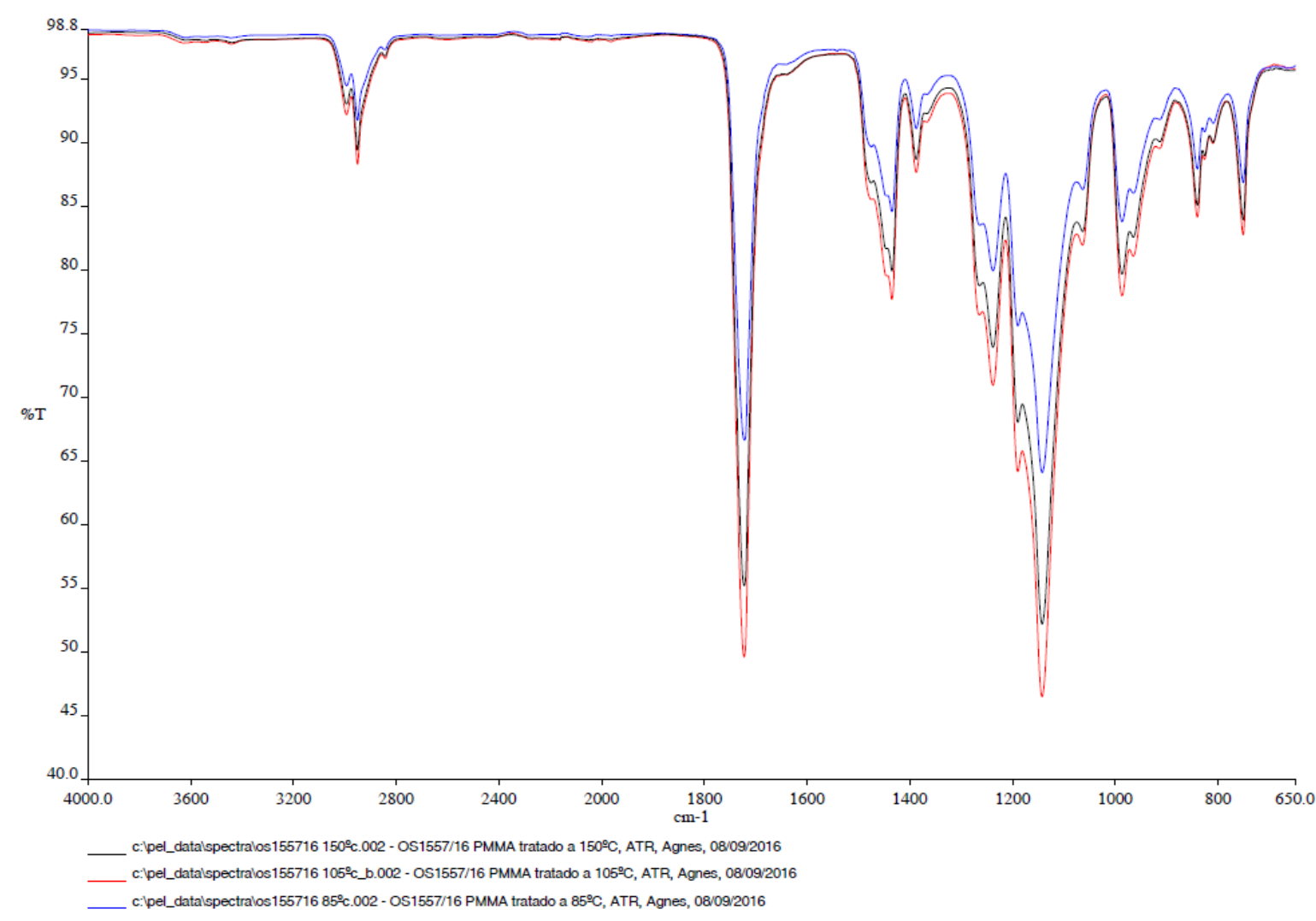

Figura 2. Sobreposição dos espectros de infravermelho da amostra do grupo B (em Azul), do grupo $C$ (em Vermelho) e do grupo D (em Preto) do PMMA.

Nota-se que as amostras tratadas termicamente apresentam o mesmo padrão de bandas que as amostras não tratadas termicamente, indicando que a temperatura não influenciou significativamente na mudança de fase do PMMA.

A figura 3 apresenta a curva TGA/DTG do PMMA. 


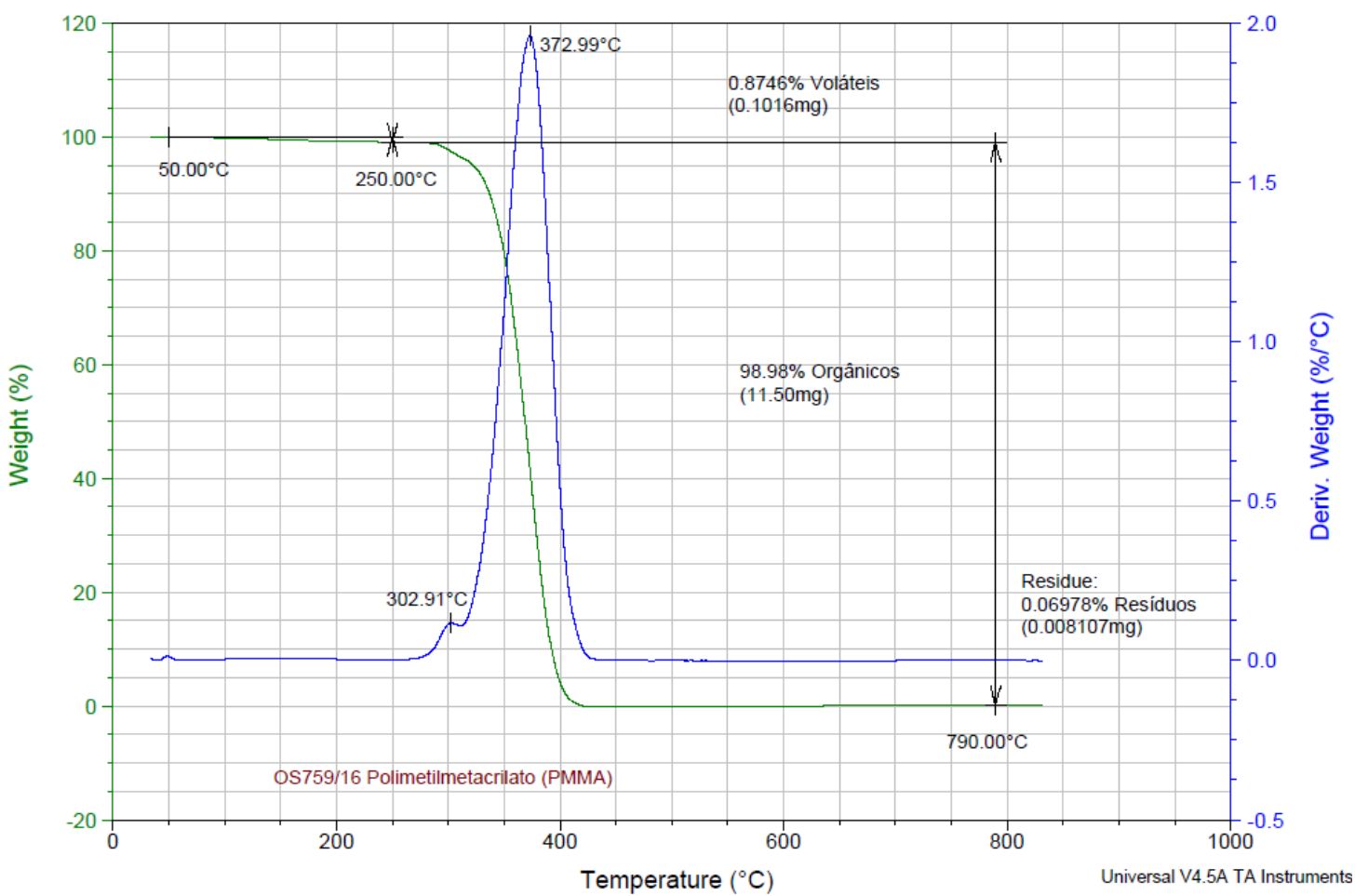

Figura 3. TG/DTG do PMMA.

Observa-se uma pequena perda de massa próxima a $250^{\circ} \mathrm{C}$ associada aos voláteis presentes na amostra. Entre 250 a $790^{\circ} \mathrm{C}$ observa-se nova perda de massa, aproximadamente de 98,98\%, associada à degradação da fração orgânica. estudadas.

A tabela 2 apresenta os resultados obtidos por TG/DTG de todas as amostras

Tabela 2. Comportamento termogravimétrico do PMMA

\begin{tabular}{l|c}
\hline & PMMA Como recebido \\
\hline (1) Perda de peso de $50^{\circ} \mathrm{C}$ até $250^{\circ} \mathrm{C}$ & $0,9 \%$ \\
(2) Perda de peso de $250^{\circ} \mathrm{C}$ até $790^{\circ} \mathrm{C}$ & $99,0 \%$ \\
(3) Resíduos a $790^{\circ} \mathrm{C}$ & $0,1 \%$ \\
\hline & PMMA Tratado a $\mathbf{8 5}{ }^{\circ} \mathbf{C}$ \\
\hline (1) Perda de peso de $50^{\circ} \mathrm{C}$ até $250^{\circ} \mathrm{C}$ & $0,7 \%$ \\
(2) Perda de peso de $250^{\circ} \mathrm{C}$ até $790^{\circ} \mathrm{C}$ & $99,0 \%$ \\
(3) Resíduos a $790^{\circ} \mathrm{C}$ & $0,3 \%$ \\
\hline & PMMA Tratado a $\mathbf{1 0 5}{ }^{\circ} \mathbf{C}$ \\
\hline (1) Perda de peso de $50^{\circ} \mathrm{C}$ até $250^{\circ} \mathrm{C}$ & $0,8 \%$ \\
(2) Perda de peso de $250^{\circ} \mathrm{C}$ até $790^{\circ} \mathrm{C}$ & $98,7 \%$ \\
(3) Resíduos a $790^{\circ} \mathrm{C}$ & $0,5 \%$ \\
\hline & PMMA Tratado a $\mathbf{1 5 0} \mathbf{0}^{\circ} \mathbf{C}$ \\
\hline (1) Perda de peso de $50^{\circ} \mathrm{C}$ até $250^{\circ} \mathrm{C}$ & $0,7 \%$ \\
(2) Perda de peso de $250^{\circ} \mathrm{C}$ até $790^{\circ} \mathrm{C}$ & $99,0 \%$ \\
(3) Resíduos a $790^{\circ} \mathrm{C}$ & $0,3 \%$ \\
\hline
\end{tabular}

As amostras tratadas termicamente apresentaram um comportamento térmico similar ao das amostras de PMMA sem tratamento térmico, figura 3 . Em todas as amostras são observadas três perdas de massa, a primeira, entre 50 e $250^{\circ} \mathrm{C}$, 
associada à eliminação dos materiais voláteis tais como plastificantes, estabilizantes e outros aditivos. A segunda, entre 250 e $790^{\circ} \mathrm{C}$ associada à degradação dos seguimentos rígidos da cadeia e a terceira, acima de $790^{\circ} \mathrm{C}$, associada à eliminação de óxidos metálicos e cargas inorgânicas.

A figura 4 apresenta a resistência em tração das amostras não tratadas termicamente e tratadas termicamente.

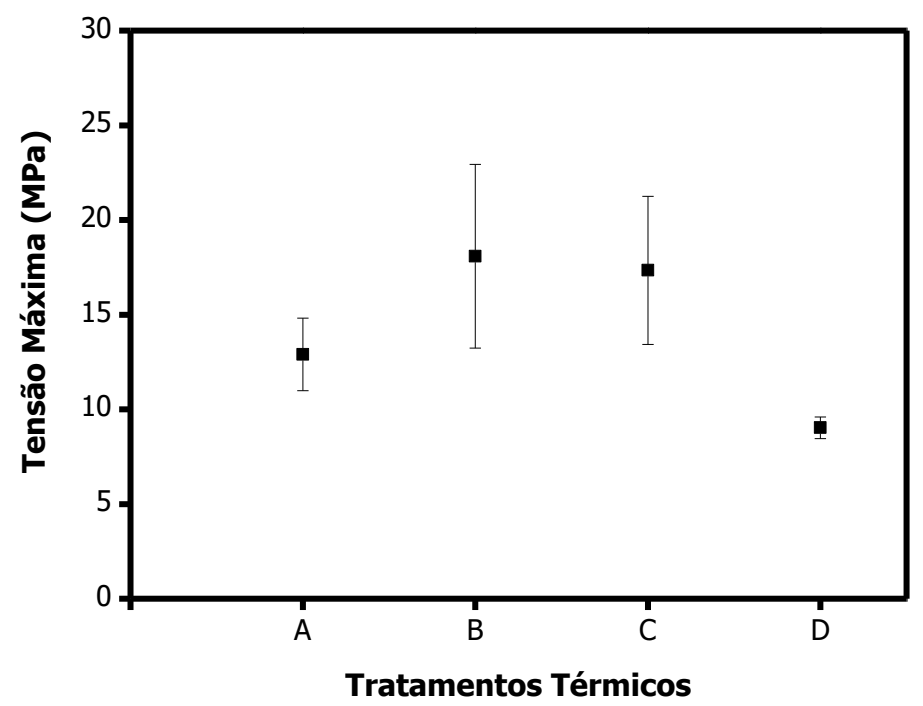

Figura 4. Resistência em Tração das amostras não tratadas e tratadas termicamente.

O ensaio de tração revelou que, dentro de um erro estatístico, o tratamento térmico não influenciou significativamente nos valores de tensão máxima, exceto nas amostras tratadas a $150^{\circ} \mathrm{C}$ que apresentou o menor valor médio para essa propriedade. De maneira geral, pode-se afirmar que tanto as amostras não tratadas termicamente quanto às amostras tratadas termicamente apresentaram um comportamento frágil.

Os resultados apresentados, apesar de diferirem dos observados em outros trabalhos, estão muito próximos aos encontrados na literatura, sendo o PMMA tratado a 85 e $105^{\circ} \mathrm{C}$ o que obteve valores médios mais próximos aos observados por outros autores [5, 9,10].

A figura 5 apresenta a resistência ao impacto Izod das amostras não tratadas termicamente e das amostras tratadas termicamente. 


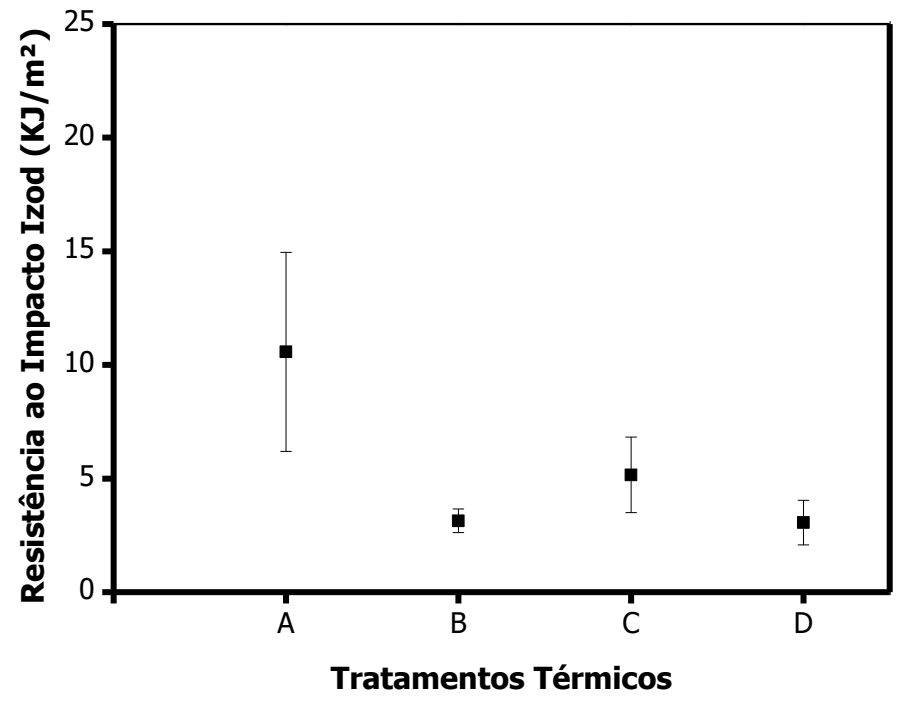

Figura 5. Resistência ao Impacto Izod. Tratamentos térmicos: A - como recebido; B Tratado termicamente a $85^{\circ} \mathrm{C} ; \mathrm{C}$ - Tratado termicamente a $105^{\circ} \mathrm{C}$; D - Tratado termicamente a $150^{\circ} \mathrm{C}$.

O teste de impacto Izod revelou que as amostras que não receberam tratamento térmico apresentaram maior resistência média ao impacto Izod e que entre as amostras tratadas termicamente não houve, dentro de um erro estatístico, variação nos valores dessa propriedade. A diminuição da resistência ao impacto nas amostras tratadas termicamente é um indicativo que a instabilidade térmica influencia na energia de impacto absorvida pelo material.

A figura 6 apresenta a micrografia obtida por microscopia eletrônica de varredura das amostras não tratadas termicamente e das amostras tratadas termicamente. 


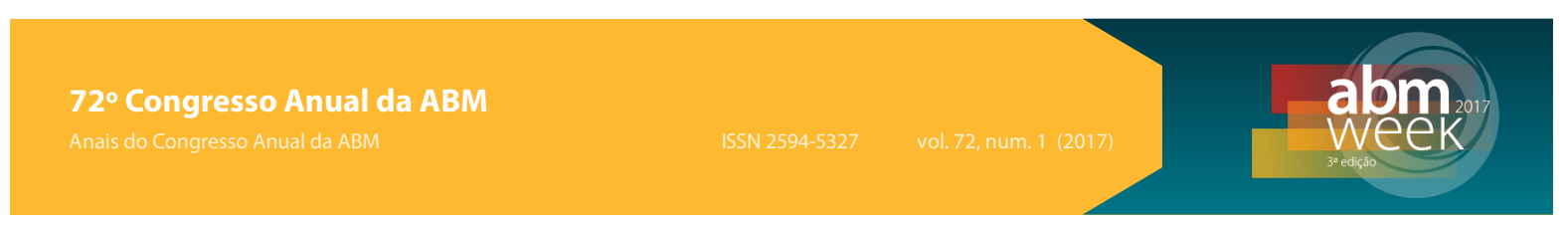

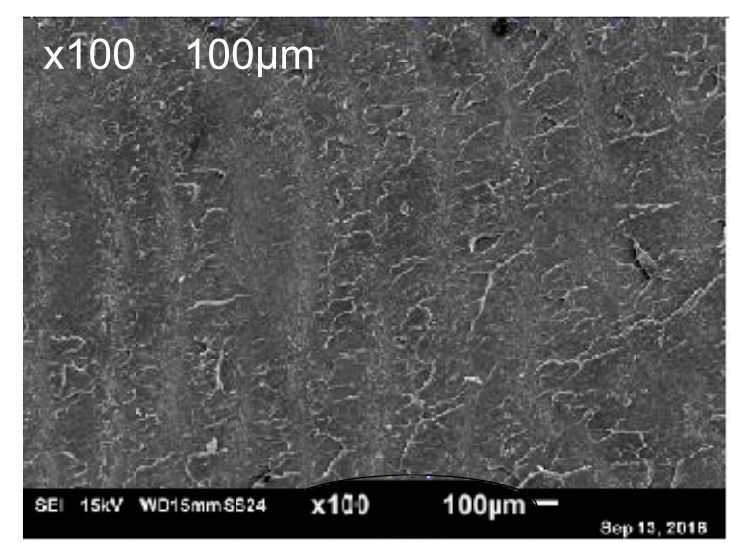

(a)

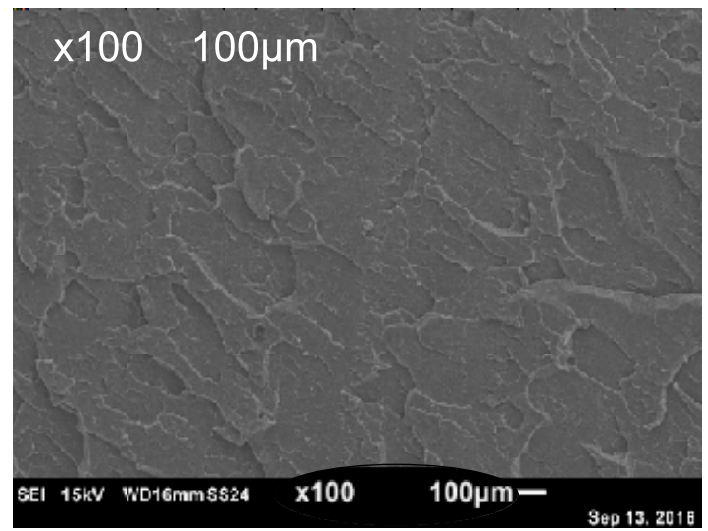

(c)

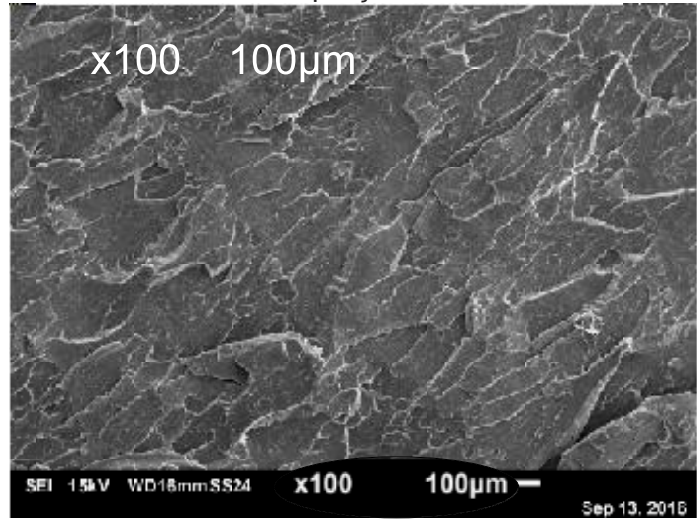

(b)

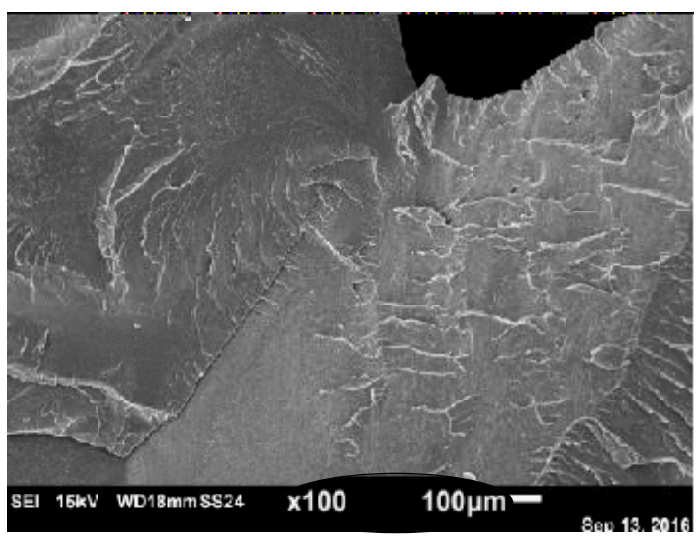

(d)

Figura 6. Micrografias obtidas por microscopia eletrônica de varredura da região da fratura das amostras ensaiadas em impacto Izod. (a) Como recebido; (b) Tratamento térmico de $105^{\circ} \mathrm{C}$; (c) Tratamento térmico de 105우 $\mathrm{C}$; (d) tratamento térmico de $150^{\circ} \mathrm{C}$.

A análise da região da fratura revelou que todas as amostras apresentaram uma superfície com marca de rio e regiões de delaminação o que caracteriza que os corpos de prova se comportaram de maneira frágil. Nas amostras tratadas a $150^{\circ} \mathrm{C}$ são observados poros que podem ter atuado como concentradores de tensão fragilizando o material. Esse fato explica os baixos valores de resistência ao impacto obtidos para essas amostras.

Assim o mapeamento das propriedades mecânicas do polimetacrilato de metila revelou que a temperatura pode ser uma variável que pode contribuir para aumentar a resistência à tração, entretanto, parece influenciar negativamente na resistência ao impacto Izod induzindo a uma fratura frágil nesse polímero.

\section{CONCLUSÃO}

O estudo sobre a influência da temperatura nas propriedades mecânicas do polimetacrilato de metila revelou que:

- O tratamento térmico não influenciou significativamente na mudança de fase do PMMA, uma vez que há uma sobreposição das bandas das amostras tratadas termicamente sobre a amostra não tratada termicamente.

- O PMMA é termicamente estável até, aproximadamente, $240^{\circ} \mathrm{C}$. Após essa temperatura o polímero sofre uma perda de massa 98,98\% o que indica que esse material pode ser utilizado em temperaturas que não ultrapassem $240^{\circ} \mathrm{C}$. 
- Amostras de PMMA tratadas a 85ㄷ apresentaram maiores valores de tensão máxima em tração. Já o tratamento térmico a $150^{\circ} \mathrm{C}$ reduziu o valor dessa propriedade, indicando que temperaturas iguais superiores a $150^{\circ} \mathrm{C}$ pode induzir uma fragilização do material.

- O tratamento térmico influenciou negativamente na resistência ao impacto do PMMA.

- A presença de marcas de rio na região da fratura do PMMA indica que esse material apresenta um comportamento frágil.

\section{REFERÊNCIAS}

1 Callister Jr. WD. Ciência e Tecnologia de Materiais: uma introdução. 8 ed. Rio de Janeiro. LTC, 2012.

2 Canaverolo Jr. SV. Ciência dos polímeros. $8^{\circ}$ Ed. São Paulo, Editora Artliber, 2006.

3 Mano EB e Mendes LC. Introdução a polímeros. São Paulo, Edgard Blücher Ltda., 2001

4 Mano E. B. Polímeros como materiais de engenharia. São Paulo: Edgard Blücher, 2000.

5 Lee DC. Preparation and characterization of PMMA-Clay hybrid composite by emulsion polymerization. Journal Applied Polymer Science. 1996;61: 1117-1123.

6 Billmeyer Jr. FW. Textbook of polymer science, New York, Wiley-Interscience, 1984.

7 Parkinson WW, Sisman O. The use of plastics and elastomers in nuclear radiation Original. Elsevier. 1971.

8 Huang CF, Chang FC. Comparison of hydrogen bonding interaction between PMMA/PMAA blends and PMMA-co-PMAA copolymers. Polymer. 2003;44:2965-2974.

9 Dommen Z.; Premalatha CK, Kuriakose B, Thomas S. Meltrheologycal behaviour of material rubber/poly (methyl methacrylate) natural rubber - g-poly(methyl methacrylate) blends. Polymer. 1997;38: 5611-5625.

10 Choi SY, Choi MH, Wang KH, Kim SO, Kim YK, Chung IJ. Synthesis of Exfoliated PMMA/Na-MMT nanocomposite via soap-free emulsion polymerization. Macromolecules, 2001; 34: 8978-8985.

11 Biasci I, Aglietto M, Ruggeri G, Ciardelli F. Functionalization ofmontmorillonite by methyl methacrylate polymers containing side-chain ammonium cations. Polymer. 1994; 35 : 3296-3004.

12 Vaia RA, Ishii H, Giannelis EP. Synthesis and properties of two dimensional nanostructures by direct intercalation of polymer melts in layeredsilicates. Chemical Materials. 1993; 5: 1694-6, 1993.

13 Okamoto M, Morita S, Taguchi H, Kim YH, Kotaka T, Tateyama H. Synthesis and structure of smetio clay-poly(methyl methacrylate) and claypolystyrene nanocomposites via in situ intercalative polymerization. Polymer. 2000; 41: 3887-3890.

14 American Society for Testing and Materials. ASTM D788-12. Standard Classification System for Poly(Methyl Methacrylate) (PMMA) Molding and Extrusion Compounds, 2012.

15 American Society for Testing and Materials. ASTM D638-10 .Standard test method for tensile properties of plastics, PA, 2010.

16 American Society for Testing and Materials. ASTM D256-10 Test Methods for Determining the Izod Pendulum Impact Resistance of Plastics. PA, 2010.

17 Rajendran S, Sivakumar M, Subadevi R. Investigations on the effect of various plasticizers in PVA-PMMA solid polymer blend electrolytes. Materials Letters. 2004; 58 (5): 641-649. 